MERCADOLOGIA 


\title{
LEALDADE DOS CLIENTES DE RESTAURANTES SELF-SERVICE
}

\author{
LOYALTY OF SELF-SERVICE RESTAURANT CUSTOMERS
}

Roberta Fundão Correia de Freitas

Fucape Business School

Emerson Wagner Mainardes

Fucape Business School

Data de submissão: 30 nov. 20 | 8. Data de aprovação:

12 fev. 2019 . Sistema de avaliação: Double blind review.

Universidade FUMEC / FACE. Prof. Dr. Henrique Cordeiro

Martins. Prof. Dr. Cid Gonçalves Filho.

Cristiane Antonietto Portugal

Fucape Business School

\section{RESUMO}

Esta pesquisa teve como objetivo identificar os antecedentes da lealdade dos clientes de restaurantes self-service. Foi proposto um modelo teórico relacionando lealdade, lembranças e associações da marca, valor percebido, qualidade geral percebida e os construtos da escala Qualidade Percebida nos Serviços. A aplicação do questionário obteve 355 respostas. A técnica de análise de dados utilizada foi a Modelagem de Equações Estruturais. Os resultados indicaram que o valor percebido e a qualidade geral percebida tendem a influenciar positivamente a lealdade dos clientes de restaurantes self-service. E três dos cinco construtos da escala QPS, aspectos físicos, soluções dos problemas e políticas internas, tendem a influenciar a percepção de qualidade dos consumidores de restaurantes self-service. Concluiu-se que, quanto maior for a qualidade geral percebida dos serviços dos restaurantes self-service, e quanto mais eles acrescentarem valor a alimentação dos clientes, provavelmente maior será a lealdade de seus clientes. Como contribuição, destaca-se que os resultados encontrados aqui indicam serem novidade na literatura, visto que não foram encontradas pesquisas sobre esse tipo de restaurante. Apesar do setor de restaurantes ser extensamente investigado, o tipo self-service não demonstra ter sido estudado anteriormente, sendo esta a lacuna de conhecimento tratada neste estudo, resultando nos antecedentes de lealdade dos clientes de self-service.

\section{PALAVRAS-CHAVE}

Lealdade de Clientes.Valor Percebido. Qualidade Geral Percebida. Restaurantes self-service. 


\section{ABSTRACT}

This research sought to identify the antecedents of the loyalty of self-service restaurant customers. It was proposed a theoretical model relating loyalty, brand remembrance and associations, perceived value, perceived general quality and the constructs of the Retail Services Quality scale.The application of the questionnaire obtained 355 responses. The data analysis technique was the Modeling of Structural Equations. The results indicated that perceived value and perceived general quality tend to positively influence the loyalty of self-service restaurant customers. And three of the five constructs of the RSQ scale, physical aspects, problem solving and internal policies, tend to influence consumer perceptions of self-service restaurants. It was concluded that the greater the overall perceived quality of self-service restaurant services, and the more they add value to customers' food, the greater the loyalty of their customers. As a contribution, it is worth noting that the results found here are unpublished in the literature, since no research was found on this type of restaurant. Although the restaurant sector is extensively investigated, the self-service type does not demonstrate that it was previously studied, this being the knowledge gap addressed in this study, resulting in the loyalty antecedents of self-service clients.

\section{KEYWORDS}

Customer Loyalty. Perceived Value. General Quality Perceived. Self-service restaurants.

\section{INTRODUÇÃO}

Atualmente, observa-se que o hábito de fazer as refeições fora de casa está longe de ser uma exceção, transformou-se em uma regra (HONICKY; SCHWARZ; VIEIRA et al., 2017). No caso brasileiro, este costume intensificou-se com o advento dos restaurantes self-service ou por quilo. Os brasileiros gastam cerca de $34 \%$ da sua renda com alimentação fora do lar (EXAME, 2017). Dados da Associação Brasileira das Indústrias da Alimentação (ABIA, 20I7) mostram que este mercado (food service) apresenta um crescimento médio anual superior a 10\%. Para os empresários desse ramo alimentício, clientes que efetuam consumo diário em seus estabelecimentos são primordiais para a sustentabilidade do negócio. Nesse contexto, a lealdade, que é vista como um elemento relevante para a captação e retenção de clientes, deixa consequências no comportamento consumidor. Dentre essas consequências, estão a recompra, a formação de laços afetivos e a menor sensibilidade a preços (FRAERING; MINOR, 2013).

Entre os estudos anteriormente realizados, Hyun (2010) procurou examinar as conexões entre a qualidade do relacionamento empresa-cliente e a formação da relação de lealdade no segmento de cadeias de restaurantes. Lee, Khan, $\mathrm{Ha}$ et al. (2017) escolheram uma cadeia de restaurantes fast-food e examinaram os principais atri- 
butos de qualidade do serviço (atendimento e serviço oferecido) que afetam a lealdade dos consumidores coreanos; Honicky, Schwarz, Vieira et al. (2017) avaliaram a satisfação dos clientes de restaurantes fastfood quanto aos serviços oferecidos e suas escolhas alimentares, e concluíram que o atendimento, a aparência, o sabor, o odor e a temperatura dos alimentos e a limpeza do ambiente são os critérios mais relevantes quando da escolha de um restaurante self-service.. No entanto, por se tratar de um fenômeno brasileiro, os restaurantes self-service não se constituíram objeto de estudo por pesquisadores estrangeiros. Neste caso, a literatura científica nacional tem se dedicado a aspectos específicos dos restaurantes self-service como estratégia operacional (REBELATO, 1997), o crescimento do mercado (LEAL, 20I0), satisfação e escolhas alimentares (HONICKY; SCHWARZ; VIEIRA et al., 20 I7). Já as relações de lealdade estabelecidas entre estes restaurantes e seus clientes apresenta-se como uma lacuna que este estudo pretendeu tratar.

Este trabalho adota a definição de lealdade do cliente como o reconhecimento de uma relação especial, que cria um vínculo como resultado do relacionamento entre o cliente e o serviço, a defesa e reforço desta relação (AKSOY; KEININGHAM; BUOYE et al., 20I5). Considerando isso, o presente estudo objetivou identificar os antecedentes diretos e indiretos da lealdade de clientes de restaurantes self-service. Sendo assim, buscou-se verificar se os aspectos físicos, a confiança, as relações pessoais, as soluções dos problemas e as políticas internas influenciam na qualidade percebida do serviço e verificar se a qualidade percebida do serviço, as lembranças e associações da marca e o valor da marca influenciam na lealdade dos clientes de restaurantes self-service.

No Brasil, o segmento de restaurantes self-service possui uma alta representatividade no consumo de alimentação fora do lar, e com potencial de crescimento. É a partir desse cenário que se dá a importância de contribuir teoricamente estudando o que gera a lealdade dos clientes de restaurantes self-service. Este tipo de restaurante possui autosserviço, ou seja, cada cliente monta sua própria refeição sem necessitar do atendimento de algum funcionário. Tendo em vista que o atendimento é um fator já verificado como influenciador da lealdade dos clientes, e o mesmo ocorre de forma pontual pela equipe de restaurantes self-service, o serviço nesse tipo de estabelecimento tende a não construção da lealdade de seus clientes, o que exige o entendimento sobre o que pode levar a lealdade dos clientes de restaurantes selfservice, sendo esta a principal contribuição deste estudo (KIM; LEE; MATTILA, 20I4; WIESEKE; ALAVI; HABEL, 20I4; KANDAMPULLY; ZHANG; BILGIHAN, 20I 5).

Como a lealdade dos clientes neste tipo de estabelecimento é mais difícil de ser gerada, visto que os clientes são muito variados e há alta rotatividade de clientes (LEAL, 20 I0; FIGUEIRÊDO; RODRIGUEZ; BARROS, 20I5), o presente estudo pretendeu também identificar as diferenças entre a lealdade dos clientes de restaurantes self-service e demais restaurantes onde a lealdade já foi objeto de estudo, gerando outra contribuição teórica desta pesquisa. Como contribuição prática, os resultados poderão auxiliar os gestores do segmento de restaurantes self-service em aspectos que vão do planejamento do negócio à 
construção dos seus planos de marketing. Traz benefícios à definição de seu diferencial competitivo, uma vez que entender o comportamento de compra de seus clientes é fundamental para a sustentabilidade e sucesso do empreendimento.

\section{REFERENCIALTEÓRICO}

Dentro do setor de bares e restaurantes brasileiros, o segmento self-service tem ganhado importância como negócio para micro e pequenos empresários que buscam atender a demanda por um tipo de alimentação fora de casa. $O$ processo de urbanização valorizou a praticidade, redução do tempo para o preparo dos alimentos e a facilidade de seu consumo, movimentando o segmento de alimentação fora do domicílio, como em restaurantes self-service (PIGATTO, 20I7), que possui peculiaridades, como o cliente servir-se a si mesmo, raramente conta com garçons, geralmente pratica preços inferiores a restaurantes a la carte, há possibilidade de personalização do prato (diferindo do fast food), entre outros. $O$ usuário de restaurantes self-service é constituído de trabalhadores de empresas públicas e privadas, estudantes, executivos e famílias, que residem, estudam ou desenvolvem suas atividades profissionais nas proximidades destes restaurantes. (LEAL, 20I0).

A principal refeição feita fora do domicílio é o almoço, e os serviços mais procurados são os rápidos e práticos, como self-service. (LEAL, 20I0). A modalidade self-service passou a oferecer uma variedade de alimentos e preparações diferentes das redes de refeições prontas e pode proporcionar um diferencial ao consumidor, que é a rapidez desejada e alimentação variada. $O$ desafio de atender aos consumidores envolve alguns fatores como atri- butos do alimento, atendimento, ambiente, tempo de espera, segurança, cardápio, privacidade, atributos de bebida, decoração, limpeza, entre outros (LEAL, 20I0).

\section{Lealdade dos Clientes}

Seguindo as proposições de Oliver (1999), Wieseke, Alavi e Habel (2014) e Larán e Espinosa (2004) descrevem a lealdade como a existência de um comprometimento profundo em comprar ou utilizar novamente um produto ou serviço, resultando em compras repetidas, mesmo com a presença de influências situacionais e esforços de marketing dos concorrentes. A lealdade também pode ser definida como um fenômeno construído ao longo do tempo, que demanda avaliações sucessivas dos processos de troca relacionais, diferente da satisfação, que pode ocorrer tanto de forma episódica como continuada (OLIVER, 1999; LARÁN; ESPINOSA, 2004). A lealdade não é apenas compra repetida, uma vez que a lealdade de verdade inclui, além do comportamento, uma resposta atitudinal, constituída por componentes cognitivos e afetivos (LARÁN; ESPINOSA, 2004). Wieseke, Alavi e Habel (20l4) demonstraram que as relações entre a lealdade do cliente e a geração de resultados para a empresa são fortes.

Percebe-se que a lealdade dos clientes é fundamental para garantir a manutenção do negócio e muitas variáveis podem estar associadas a ela (OLIVER, 1999). Assim, os gestores de restaurantes self-service, ao conhecerem as variáveis que influenciam a lealdade dos clientes, podem utilizar estas informações para melhorarem suas estratégias e investimentos (LARÁN; ESPINOSA, 2004).

\section{Lembranças e Associações da Marca}

As lembranças e associações fazem com 
que consumidores optem por uma marca conhecida mesmo que ela seja inferior as concorrentes. Lembranças da marca é uma das dimensões mais mencionadas em pesquisa com empresas. Assim sendo, o valor emocional pode impactar uma marca de modo a se sobressair em relação a outros atributos (YOO; DONTHU, 200I; KATHURIA; GILL, 2013 ).

Existem relações diretas entre o processo de compra e a identidade visual das marcas (FIGUEIRÊDO; RODRIGUEZ; BARROS, 20I5). Elementos que associam as marcas dos restaurantes com os sabores comercializados ou com o tipo de comida oferecido são diretamente responsáveis pela decisão de consumo.Ao escolher a marca como um elo com o cliente, que vai muito além da qualidade do produto, a imagem se converte em um fator decisivo para a escolha da mesma (YOO; DONTHU, 200I; KATHURIA; GILL, 20I3). Portanto, levando em conta que este estudo foi direcionado para o segmento de restaurantes self-service, sugeriu-se que as lembranças e associações da marca geram uma influência positiva na lealdade dos consumidores.Assim sendo, a primeira hipótese proposta foi:

$\mathrm{HI}$ : As lembranças e associações das marcas de restaurantes self-service influenciam positivamente a lealdade dos clientes.

\section{Valor Percebido}

$O$ valor percebido da marca tem sido considerado um dos mais importantes conceitos para entender os consumidores. $O$ valor percebido pode ser entendido como um trade-off entre os benefícios percebidos pelo consumidor e o valor despendido por ele (ZEITHAML, I988; PERMARUPAN; MOHAN;AL-MAMUN et al., 20I4). Em relação a serviços, alguns atributos possuem mais influência na percepção de valor por parte do consumidor. Essa influência pode advir do peso ou importância que os clientes relacionam a esses atributos. $A$ identificação desses atributos estabelece uma relação de lealdade com os consumidores e possibilita a adequação da oferta do serviço (ESPINOZA; HIRANO, 2003).

Bacelar, Trinta e Campomar (2010) verificaram que o valor percebido pode ser avaliado por meio do comportamento do consumidor. Nesse processo, uma das principais dimensões é a lealdade dos clientes. O processo de geração de lealdade relaciona-se à avaliação dos atributos extrínsecos e intrínsecos do serviço ou produto por parte do consumidor, levando-o a perceber os níveis de qualidade, preço e valor das diferentes alternativas no momento da escolha do cliente (ZEITHAML, 1988; PERMARUPAN; MOHAN; AL-MAMUN et al., 20I4). Como observado na literatura, pode-se sugerir que o valor percebido é um dos antecedentes da lealdade dos clientes de restaurantes self-service. Assim, a segunda hipótese proposta foi:

$\mathrm{H}$ 2: $\mathrm{O}$ valor percebido pelos clientes de restaurantes self-service influencia positivamente a lealdade dos clientes.

\section{Qualidade Percebida em Serviços (QPS)}

Observa-se na literatura que há variadas dimensões responsáveis pela qualidade percebida em restaurantes: atendimento, conforto, localização, comodidade, valor percebido, possibilidade de escolha, estacionamento entre outras (AZEVEDO; MOURA; SOUKI, 20I5). Isso tudo para garantir que o consumidor tenha suas expectativas atendidas, trazendo a percepção de qualidade e gerando estímulo 
para o cliente tecer comentários e recomendações positivas para outras pessoas. Por consequência, pode-se construir a lealdade dos clientes. Trata-se de um fato positivo para os restaurantes, visto que as recomendações de pessoas próximas que já frequentaram determinado restaurante são consideradas por muitos como a fonte de informação mais confiável para escolher a melhor opção durante o processo decisório (AZEVEDO; MOURA; SOUKI, 20I5). Em vista disso, sugeriu-se que a qualidade percebida em serviços influencie positivamente a geração da lealdade nos clientes de restaurantes self-service.Assim sendo, a terceira hipótese proposta foi:

H3: A qualidade percebida pelo cliente influencia positivamente a lealdade dos clientes de restaurantes self-service.

A qualidade geral percebida pelos indivíduos é um construto antecedido por outros construtos sobre os quais os consumidores atribuem pesos diferentes, maior ou menor (AZEVEDO; MOURA; SOUKI, 20I 5). Devido a qualidade percebida ser um construto multidimensional, esta pesquisa adotou a QPS criada por Lopes, Hernadez, Nohara (2009), que definem ela como uma adaptação da escala Retail Service Quality (RSQ) de Dabholkar, Thorpe e Rentz (1996). A mesma vem sendo utilizada nas pesquisas como uma ferramenta que proporciona um conhecimento da qualidade percebida do serviço, bem como sua ligação com outros construtos. A escala QPS é formada por cinco construtos distintos: aspectos físicos, confiança, relações pessoais, solução de problemas e políticas internas (LOPES; HERNADEZ; NOHARA, 2009).

A QPS não é somente utilizada para medir a qualidade percebida do serviço. Ela também serve para atingir objetivos como a aferição da qualidade dos serviços prestados, bem como a capacidade de atrair e reter consumidores (LOPES; HERNANDEZ; NOHARA, 2009). Na questão de atrair e reter clientes, quando um serviço é ofertado por fornecedores vizinhos e semelhantes, como é o caso dos restaurantes self-service, a escala QPS encarrega-se de identificar o elemento diferenciador entre eles. A qualidade do serviço apresenta-se convenientemente como uma forma natural de diferenciar um negócio ou serviço em um mercado competitivo (NGUYEN; LEBLANC, 200I).

O primeiro construto da escala QPS refere-se aos aspectos físicos. Os aspectos físicos são fundamentais para a construção da imagem que o cliente possui do estabelecimento. $O$ grau de lealdade do cliente tende a ser maior quando as percepções da imagem e da reputação do restaurante são favoráveis (NGUYEN; LEBLANC, 200I). É importante se preocupar com o cliente no momento da compra, fazendo com que a empresa utilize seus espaços de maneira agradável e faça um levantamento dos pontos negativos para serem melhorados (LOPES; HERNANDEZ; NOHARA, 2009).

$A$ aparência do local onde o serviço é prestado é usada pelo consumidor como um indício para julgar a qualidade do estabelecimento. Além disso, também é utilizada como uma maneira da empresa diferenciar a sua oferta e influenciar diretamente na experiência do serviço. No caso dos restaurantes, a apresentação dos pratos, o sabor, os aromas, a higiene e o serviço são fundamentais no processo de percepção de qualidade do consumidor (FIGUEIRÊDO; RODRIGUEZ; BARROS, 20 I5). Considerando isso, no segmento de restaurantes self-service, sugere-se que os aspectos físi- 
cos geram influência positiva na percepção de qualidade do cliente. Nesse sentido, a quarta hipótese proposta foi:

H4: Os aspectos físicos de restaurantes self-service influenciam positivamente a qualidade percebida pelo cliente.

Quanto a confiança, construto também presente na escala QPS, Rosseau, Sitkin, Burt et al. (1998) a definem como um estado psicológico que compreende a intenção de aceitar a vulnerabilidade focando em expectativas positivas de intenções ou comportamento do outro. Afirma-se que a confiança está relacionada à disposição dos consumidores em contar com um parceiro de trocas (KANTSPERGER; KUNZ, 2010). Apesar da satisfação e do comprometimento influenciarem as intenções de relacionamento com o cliente, a confiança é variável fundamental nos relacionamentos entre consumidores e empresas, pois pode influenciar a qualidade percebida do serviço (GAMBARINO; JOHNSON, 1999). Nesse sentindo, esta pesquisa sugeriu que a confiança influencia positivamente a qualidade percebida. Assim sendo, a quinta hipótese proposta foi:

H5:A confiança influencia positivamente a qualidade percebida pelo cliente de restaurantes self-service.

Outro construto também abordado na escala QPS é o referente a relações pessoais. Boa parte das estratégias de negócios em serviços é construída em torno da retenção de clientes, e relacionamentos fortes com clientes dependem, por sua vez, de interações e experiências que atendem e excedem as expectativas deles (LAX, 20I2). É importante ressaltar que as emoções positivas influenciam a qualidade percebida dos clientes de forma mais forte do que as emoções negativas (RYCHALSKI;
HUDSON, 2017). As boas relações pessoais entre o fornecedor e os clientes são fontes de valor agregado, gerando benefícios para os serviços e produtos (DORNAS; MESQUITA; PATROCÍNIO, 20I4). Exemplo desses benefícios é a qualidade percebida pelos clientes. Por meio desta perspectiva, sugeriu-se que as relações pessoais possuem influência positiva na qualidade percebida do serviço pelos clientes. Assim sendo, a sexta hipótese proposta foi:

H6: As relações pessoais influenciam positivamente a qualidade percebida pelo cliente de restaurantes self-service.

Solução dos problemas também é um construto contido na escala QPS. Pode-se afirmar que é indispensável para a empresa mostrar que seus funcionários têm capacidade de atender satisfatoriamente cada cliente, fazendo com que eles obtenham experiências positivas (OLIVEIRA; MARCONDES; MALERE et al., 2009). A percepção do serviço pelo consumidor tem influência na intenção de continuar utilizando o serviço e de recomendá-lo (WIEN; OLSEN, 20I2). A solução dos problemas realizada de maneira eficaz em restaurantes self-service tende a estar associada a qualidade percebida do serviço, que está diretamente ligada a percepção da qualidade ou superioridade de um serviço em relação à sua funcionalidade e às suas alternativas (LOPES; HERNANDEZ; NOHARA, 2009). Neste sentido, esta pesquisa sugeriu que a solução dos problemas influência de maneira positiva a percepção de qualidade dos clientes. Desta forma, surgiu a sétima hipótese proposta:

H7:As soluções dos problemas nos restaurantes self-service influenciam positivamente a qualidade percebida pelo cliente.

último construto presente na escala 
QPS refere-se às políticas internas. A política interna de um restaurante deve conter informações relacionadas ao ambiente de trabalho, o uso de equipamentos de segurança, $O$ atendimento ao cliente. $A$ equipe deve incorporar no seu trabalho a cultura da empresa e todos os esforços por parte dos gestores para melhorar o atendimento, produtividade e o relacionamento (LOPES; HERNANDEZ; NOHARA, 2009). Estudos realizados apontam as relações positivas entre as políticas internas e a qualidade percebida do serviço (OLIVEIRA; MARCONDES; MALERE et al., 2009). Corroborando com essa ideia, esta pesquisa sugeriu que as políticas internas tendem a influenciar a qualidade percebida dos clientes de restaurantes self-service.Assim sendo, a oitava hipótese proposta foi:

H8: As políticas internas dos restauran- tes self-service influenciam positivamente a qualidade percebida pelo cliente.

\section{Modelo Proposto}

A partir das hipóteses construídas, a Figura I apresenta o modelo desenvolvido para esta pesquisa. $O$ modelo proposto contempla a influência positiva que os construtos lembranças e associações da marca, valor percebido e qualidade percebida exercem diretamente na lealdade dos clientes de restaurantes self-service. Além disso, reflete a influência positiva que os construtos da escala QPS (aspectos físicos, confiança, relações pessoais, solução de problemas e políticas internas) exercem diretamente na percepção geral de qualidade dos consumidores desse segmento (LOPES; HERNADEZ; NOHARA, 2009).

Um dos argumentos para a construção

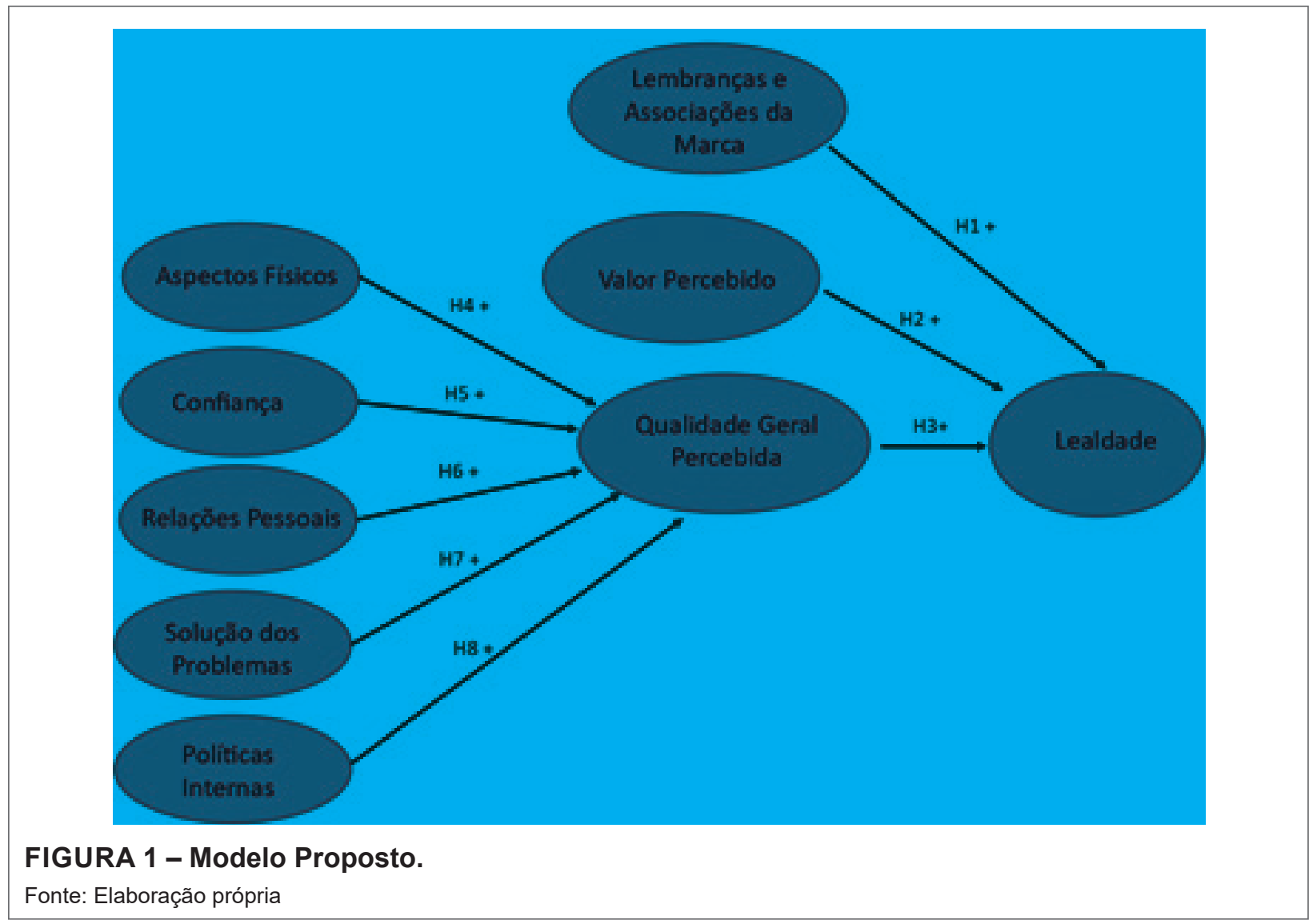


deste modelo está alicerçado no conceito que a lealdade possui antecedentes diretos e indiretos. Consequentemente, o efeito da lealdade dos consumidores impacta positivamente a manutenção e sustentação das empresas no mercado (ESPINOZA; HIRANO, 2003). Baseado em literatura existente, o modelo proposto apresenta relações diretas, em conjunto, da lealdade com seus potenciais antecedentes: lembranças e associações da marca, valor percebido e qualidade percebida (AZEVEDO; MOURA; SOUKI, 20I5). O modelo apresentado também sugere que os aspectos físicos, a confiança, as relações pessoais, as soluções de problemas e as políticas internas são antecedentes da qualidade geral percebida (BERGAMO; GIULIANI; CAMARGO et al., 20I2; PURGAILIS; ZAKSA, 20I2; SHAOCHANG, 20I3). Ao entrelaçar esse conjunto de informações, gerou-se o modelo proposto desta pesquisa.

\section{METODOLOGIA DE PESQUISA}

O método escolhido para a realização do estudo foi uma pesquisa descritiva, quantitativa, com utilização de dados primários e corte transversal. Definiu-se restaurante self-service como restaurantes onde o valor do prato é medido pelo peso da comida. Por este motivo, popularmente no Brasil, os restaurantes self-service também são conhecidos por "restaurantes por quilo". A população alvo foi composta por qualquer indivíduo brasileiro que afirmou conhecer algum restaurante self-service. A amostra desta pesquisa foi composta por 355 indivíduos que afirmaram conhecer algum restaurante self-service. Tais indivíduos declararam ser conhecedores de restaurantes self-service. Buscou-se alcançar uma amostra o mais heterogênea possível.
Por isso, não se segmentou a amostra, evitando grupos específicos de indivíduos, divulgando-se o questionário de modo geral, sem critérios de escolha de respondente. Este tipo de amostra caracteriza-se por ser não probabilística (buscou-se evidenciar comportamentos sem estabelecer probabilidades) e por acessibilidade (alcançou-se quem foi possível alcançar).

$O$ instrumento de coleta de dados primários foi um questionário composto de 52 questões, sendo a primeira afirmação do questionário uma questão de controle ("Você conhece algum restaurante selfservice?") para identificar se o respondente pertencia à população-alvo do estudo. Desta forma, caso o respondente afirmasse não conhecer, seria excluído da amostra. Além desta questão, o questionário contemplou as 19 variáveis presentes nos construtos validados por Murad e Torres (2008). As questões 2 a 4 avaliaram a lealdade dos clientes de restaurantes self-service. $O$ grupo de questões seguintes avaliou qualidade geral percebida pelos clientes por meio das questões 5 a 10 . As questões II a 16 trataram sobre as lembranças e associações da marca dos restaurantes selfservice. E as perguntas 17 a 20 avaliaram o valor percebido pelos clientes. Todas essas questões foram adaptadas para a pesquisa de restaurantes self-service conforme apresentadas no Apêndice.

$\mathrm{Na}$ sequência, o questionário contemplava as 28 variáveis presentes nos construtos da escala QPS (LOPES; HERNADEZ; NOHARA, 2009), adaptados para a pesquisa de restaurantes self-service. $O$ questionário foi organizado das questões 21 a 26 abordando os aspectos físicos dos restaurantes self-service. Em seguida, as assertivas 27 a 31 buscaram avaliar a confiança 
dos clientes em restaurante self-service. $\mathrm{O}$ grupo de questões seguinte avaliou as relações pessoais entre os clientes e os funcionários e proprietários de restaurantes self-service por meio das questões 32 a 40 . As questões $4 \mathrm{I}$ a 43 avaliaram a capacidade dos restaurantes self-service de solucionar os problemas dos clientes. E as assertivas 44 a 48 avaliaram as políticas internas.

Por fim, foram estabelecidas quatro perguntas para caracterizar os respondentes, com questões referentes a sexo, idade, grau de escolaridade e renda mensal. No total, 9 construtos foram avaliados por meio de afirmações de direcionamento positivo e acompanhadas por uma escala que variou de discordo totalmente $(\mathrm{I})$ a concordo totalmente (5). Todas as respostas foram confidenciais e os respondentes não foram identificados.

Foi realizado um pré-teste com 20 indivíduos que afirmaram conhecer algum restaurante self-service. Não foram identificados problemas em relação à interpretação das afirmações propostas. Assim, a coleta de dados foi iniciada. A coleta de dados online se deu por meio da distribuição do link em redes sociais, publicando o mesmo no Facebook e no Linkedin, compartilhando por Whatsapp e encaminhado por e-mail para o máximo de pessoas possível, não se limitando ao círculo de relacionamento dos pesquisadores. A aplicação do questionário ocorreu de julho a novembro de 2017 (período que o link ficou ativo) e foram obtidas 355 respostas. Nenhuma reposta foi desconsiderada, pois todos respondentes afirmaram conhecer algum restaurante self-service.

A técnica de análise de dados utilizada foi a Modelagem de Equações Estruturais, com o método de estimação de mínimos quadrados parciais (PLS). Antes do teste das relações propostas no modelo, os cons- trutos foram validados por meio da análise fatorial confirmatória. Para a validade convergente, verificou-se as cargas fatoriais, a variância média extraída e a confiabilidade composta. Para a validade discriminante, foi feita a comparação da raiz quadrada da variância média extraída com as correlações entre os construtos (FORNELL; LARCKER, I98I) e foram verificadas as cargas fatoriais. Em seguida, fez-se o teste das hipóteses do modelo estrutural proposto.

\section{ANÁLISE DE DADOS E DISCUSSÃO DOS RESULTADOS}

Os dados da amostra mostraram o seguinte perfil demográfico: a maior parte dos respondentes foram mulheres (58\%). A idade dos participantes da amostra indicou uma representação equilibrada entre adultos de 26 a 30 anos (I8\%), 3I a 35 (I5\%), 36 a 45 (26\%) e 46 a 60 (24\%). Com relação à renda mensal, a amostra apresentou equilíbrio entre todas as classes: $15 \% \mathrm{com}$ renda de $R \$ 2000,00$ ou menos; $15 \%$ entre $R \$ 2000,00$ e $R \$ 3500,00 ; 13 \%$ entre $R \$ 3500,00$ a $R \$ 5000,00 ; 16 \%$ entre $R \$$ 5000,00 a $R \$ 7500,00 ; 14 \%$ entre $R \$ 7500,00$ a $R \$ 10000,00 ; 17 \%$ entre $R \$ R \$ 10000,00$ a $R \$ 15000,00$ e $10 \%$ acima de $R \$ 15000,00$. Referente à escolaridade, constatou-se que 47 , I \% são pós-graduados e $27,4 \%$ têm ensino superior. Complementarmente, $92 \%$ dos respondentes declararam ser moradores de capitais, regiões metropolitanas ou cidades com mais de 100 mil habitantes. Observouse as características de clientes típicos de restaurantes self-service: homens e mulheres adultos, de variadas idades, com boa escolaridade, com rendas mensais variadas, moradores de grandes cidades, o que aponta a diversidade da clientela dos restaurantes self-service. 


\section{Validação do Modelo de Mensuração}

Inicialmente fez-se a análise fatorial confirmatória, que permite especificar a representação lógica e sistemática das medidas e construtos latentes envolvidos (FORNELL; LARCKER, I98I). A partir desta análise verificou-se a validade dos construtos por meio da análise das cargas fatorais na matriz fatorial, onde observou-se a necessidade de exclusão de 8 variáveis da pesquisa (AF6, CON5, LM4, LM5, PI3, PI4, QP2, RP7), restando 44 variáveis no estudo. Após, foi realizada novamente a Análise Fatorial Confirmatória (AFC), cujos resultados são apresentados na Tabela I. Após a segunda AFC, observou-se as cargas fatoriais na Tabela I. Esta apresenta cargas fatoriais altas das variáveis no seu próprio construto, maiores que 0,6 , que indicam que há validade convergente, pois indicam o carregamento da variável no próprio construto, isto é, as variáveis convergem para o seu próprio construto. Além disso, ilustram validade discriminante na comparação de cada construto com os demais, ao não serem identificadas cargas cruzadas (HAIR JR. et al., 2009).

A validade convergente também foi verificada por meio da variância média extraída - AVE (Tabela 2), pois em todos os construtos obteve-se um valor superior a 0,5, conforme recomendam Hair Jr. et al. (2009). Ainda na Tabela 2, a confiabilidade composta (CC), que também indica a validade convergente, mostrou-se robusta para todos os construtos, apresentando valores superiores a 0,7 (HAIR JR. et al., 2009). A validade discriminante, que se refere ao grau em que um construto é efetivamente distinto dos demais, também foi observada segundo o critério de Fornell e Larcker (I98I), ao verificar que a raiz qua- drada da AVE de cada construto foi superior às correlações do construto com os demais construtos (HAIR JR. et al., 2009), indicando independência entre eles (Tabela 2 - diagonal principal com fonte em negrito). Validados os construtos, prosseguiu-se com o teste do modelo estrutural.

\section{Análise e Discussão das Hipóteses}

A Figura 2 apresenta os resultados do modelo estrutural proposto na presente pesquisa. Os resultados do modelo estrutural foram analisados a partir da avaliação dos construtos individuais e seus respectivos caminhos, bem como por meio da análise dos coeficientes de determinação, especificamente as estimativas de variância explicadas para as variáveis endógenas. $O$ último passo da validação do modelo estrutural foram os testes de hipóteses.

Considerando os objetivos propostos relacionados aos antecedentes da lealdade de clientes de restaurantes self-service: identificar a influência das lembranças e associações da marca, valor percebido e qualidade geral percebida na lealdade dos clientes de restaurantes self-service; e identificar a influência dos fatores da escala QPS (aspectos físicos, confiança, relações pessoais, soluções dos problemas e políticas internas) na qualidade geral percebida do serviço pelos clientes de restaurantes self-service, a Figura 2 mostra que foram encontradas evidências para suportar a maior parte das hipóteses sugeridas. Sendo assim, o modelo estrutural foi sustentado.

A relação entre a lealdade dos clientes de restaurantes self-service e as lembranças e associações da marca, representada pela hipótese $\mathrm{I}$, não foi significativa ( $\mathrm{p}$-valor $=$ 0,09 ). Sendo assim, foi rejeitada a hipótese. Logo, neste estudo as lembranças e asso- 
TABELA 1 - Matriz de cargas fatoriais.

\begin{tabular}{|c|c|c|c|}
\hline Construtos & Códigos & Indicadores & $\begin{array}{l}\text { Carga } \\
\text { Fatorial }\end{array}$ \\
\hline \multirow[t]{5}{*}{$\begin{array}{l}\text { Aspectos físicos - AF } \\
\text { (LOPES; HERNANDEZ; } \\
\text { NOHARA, 2010) }\end{array}$} & AF1 & Restaurantes self-service normalmente tem equipamentos modernos. & 0,71 \\
\hline & AF2 & Os ambientes dos restaurantes self-service são visualmente agradáveis. & 0,69 \\
\hline & AF3 & Os materiais usados em restaurantes self-service são visualmente agradáveis. & 0,72 \\
\hline & AF4 & A limpeza dos restaurantes self-service, incluindo o banheiro, é adequada. & 0,74 \\
\hline & AF5 & O layout dos restaurantes self-service facilita o cliente encontrar o que precisa. & 0,67 \\
\hline \multirow[t]{4}{*}{$\begin{array}{l}\text { Confiança - CON (LOPES; HER- } \\
\text { NANDEZ; NOHARA, 2010) }\end{array}$} & CON1 & Quando restaurantes self-service prometem algo, cumprem dentro do que foi informado. & 0,71 \\
\hline & CON2 & Os restaurantes self-service cumprem suas promessas. & 0,76 \\
\hline & CON3 & Os restaurantes self-service sempre realizam serviços de maneira correta. & 0,79 \\
\hline & CON4 & Os restaurantes self-service mantém disponíveis os alimentos que os clientes desejam. & 0,71 \\
\hline \multirow[t]{3}{*}{$\begin{array}{l}\text { Lealdade a marca - LEA } \\
\text { (MURRAD; TORRES, 2008) }\end{array}$} & L1 & Comparando a outros tipos de restaurantes, eu me considero leal a restaurantes self-service. & 0,82 \\
\hline & L2 & Restaurante self-service é minha primeira opção. & 0,87 \\
\hline & L3 & Eu não vou a outros restaurantes se existe um restaurante self-service disponível. & 0,81 \\
\hline \multirow[t]{4}{*}{$\begin{array}{l}\text { Lembranças e associações } \\
\text { da marca - LM (MURRAD; } \\
\text { TORRES, 2008) }\end{array}$} & LM1 & Eu sei reconhecer um restaurante self-service de alto nível. & 0,81 \\
\hline & LM2 & Eu posso identificar um restaurante self-service de alto nível entre outros restaurantes. & 0,81 \\
\hline & LM3 & Eu conheço bem restaurantes self-service. & 0,77 \\
\hline & LM6 & Eu não tenho dificuldade de imaginar um bom restaurante self-service na minha cabeça. & 0,66 \\
\hline \multirow[t]{3}{*}{$\begin{array}{l}\text { Políticas Internas - PI (LO- } \\
\text { PES; HERNANDEZ; NOHA- } \\
\text { RA, 2010) }\end{array}$} & PI1 & Restaurantes self-service sempre oferecem produtos de alto padrão. & 0,84 \\
\hline & $\mathrm{PI} 2$ & Os restaurantes self-service costumam disponibilizar alternativas de estacionamento aos clientes. & 0,81 \\
\hline & PI5 & Os restaurantes self-service oferecem formas de pagamento especiais para seus clientes assíduos. & 0,67 \\
\hline \multirow[t]{5}{*}{$\begin{array}{l}\text { Qualidade Percebida - QP } \\
\text { (MURRAD; TORRES, 2008) }\end{array}$} & QP1 & Comparando a outros tipos de restaurante, restaurantes self-service são de alta qualidade. & 0,80 \\
\hline & QP3 & Se é restaurante self-service, deve ser de boa qualidade. & 0,66 \\
\hline & QP4 & Jamais restaurantes self-service são de baixa qualidade. & 0,70 \\
\hline & QP5 & A chance que um restaurante self-service seja uma boa opção é muito alta. & 0,75 \\
\hline & QP6 & A probabilidade de que restaurantes self-service sejam confiáveis é muito alta. & 0,80 \\
\hline \multirow[t]{8}{*}{$\begin{array}{l}\text { Relações pessoais - RP } \\
\text { (LOPES; HERNANDEZ; } \\
\text { NOHARA, 2010) }\end{array}$} & RP1 & Os empregados dos restaurantes self-service têm condições de sanar as dúvidas dos clientes. & 0,68 \\
\hline & RP2 & O comportamento dos funcionários dos restaurantes self-service inspira confiança nos clientes. & 0,76 \\
\hline & RP3 & Os clientes se sentem seguros em realizar refeições em restaurantes self-service. & 0,68 \\
\hline & RP4 & Os empregados dos restaurantes self-service estão sempre disponíveis para atender o cliente. & 0,76 \\
\hline & RP5 & $\begin{array}{l}\text { Os empregados dos restaurantes self-service prestam informações corretas sobre os servi- } \\
\text { ços realizados. }\end{array}$ & 0,76 \\
\hline & RP6 & $\begin{array}{l}\text { Os empregados dos restaurantes self-service estão sempre disponíveis para sanar as dúvi- } \\
\text { das dos clientes. }\end{array}$ & 0,75 \\
\hline & RP8 & Os empregados de restaurantes self-service sempre são cordiais. & 0,63 \\
\hline & RP9 & $\begin{array}{l}\text { Os empregados de restaurantes self-service atendem bem também ao telefone (encomen- } \\
\text { das, dúvidas, etc). }\end{array}$ & 0,71 \\
\hline \multirow[t]{2}{*}{$\begin{array}{l}\text { Solução de Problemas - SP } \\
\text { (LOPES; HERNANDEZ; } \\
\text { NOHARA, 2010) }\end{array}$} & SP1 & $\begin{array}{l}\text { Quando ocorre algum problema (por exemplo, derrubar o prato, excesso de sal, etc), os } \\
\text { restaurantes self-service facilitam as trocas das refeições. }\end{array}$ & 0,83 \\
\hline & SP2 & $\begin{array}{l}\text { Quando o cliente tem um problema, os restaurantes self-service mostram interesse sincero } \\
\text { em resolver. }\end{array}$ & 0,85 \\
\hline
\end{tabular}




\begin{tabular}{l|c|l|l}
\hline & SP3 & $\begin{array}{l}\text { Os empregados dos restaurantes self-service são habilitados a solucionar pessoalmente os } \\
\text { problemas dos clientes. }\end{array}$ & 0,84 \\
\hline $\begin{array}{l}\text { Valor da marca-VP } \\
\text { (MURRAD; TORRES, 2008) }\end{array}$ & VP1 & $\begin{array}{l}\text { Vale a pena se alimentar em um restaurante self-service ao invés de outros restaurantes } \\
\text { mesmo quando eles são semelhantes. }\end{array}$ \\
\hline & VP2 & $\begin{array}{l}\text { Mesmo que outros restaurantes tenham as mesmas características, eu prefiro ir em um } \\
\text { restaurante self-service. }\end{array}$ \\
\hline & VP3 & Mesmo que haja outro restaurante tão bom quanto, eu prefiro restaurantes self-service. \\
\hline & $\begin{array}{l}\text { Se outro restaurante não é em nada diferente, parece mais inteligente ir a um restaurante } \\
\text { self-service }\end{array}$ \\
\hline
\end{tabular}

Fonte: Dados da pesquisa.

TABELA 2 - Correlações e estatísticas dos construtos latentes.

\begin{tabular}{l|c|c|c|c|c|c|c|c|c|c|c}
\hline Construtos latentes & AVE & CC & AF & CON & LEA & LM & PI & QP & RP & SP & VP \\
\hline AF - Aspectos Físicos & 0,50 & 0,83 & 0,71 & & & & & & & & \\
\hline CON - Confiança & 0,55 & 0,83 & 0,52 & 0,74 & & & & & & & \\
\hline LEA - Lealdade & 0,69 & 0,87 & 0,45 & 0,41 & 0,83 & & & & & & \\
\hline LM - Lembrança da Marca & 0,59 & 0,85 & 0,36 & 0,44 & 0,28 & 0,77 & & & & & \\
\hline PI - Políticas Internas & 0,60 & 0,82 & 0,49 & 0,38 & 0,41 & 0,08 & 0,78 & & & & \\
\hline QP - Qualidade Percebida & 0,55 & 0,86 & 0,57 & 0,42 & 0,54 & 0,22 & 0,65 & 0,74 & & & \\
\hline RP - Relações Pessoais & 0,52 & 0,89 & 0,58 & 0,61 & 0,48 & 0,34 & 0,54 & 0,53 & 0,72 & & \\
\hline SP - Solução dos Problemas & 0,70 & 0,88 & 0,53 & 0,50 & 0,39 & 0,29 & 0,54 & 0,54 & 0,71 & 0,84 & \\
\hline VP - Valor da Marca & 0,65 & 0,88 & 0,45 & 0,34 & 0,58 & 0,32 & 0,39 & 0,57 & 0,40 & 0,34 & 0,81 \\
\hline FOnte: Dados da pes
\end{tabular}

Fonte: Dados da pesquisa. Legenda: AVE - average variance extracted; CC - confiabilidade composta. OBS: Números em negrito na diagonal principal indicam o valor da raiz quadrada da AVE de cada construto latente.

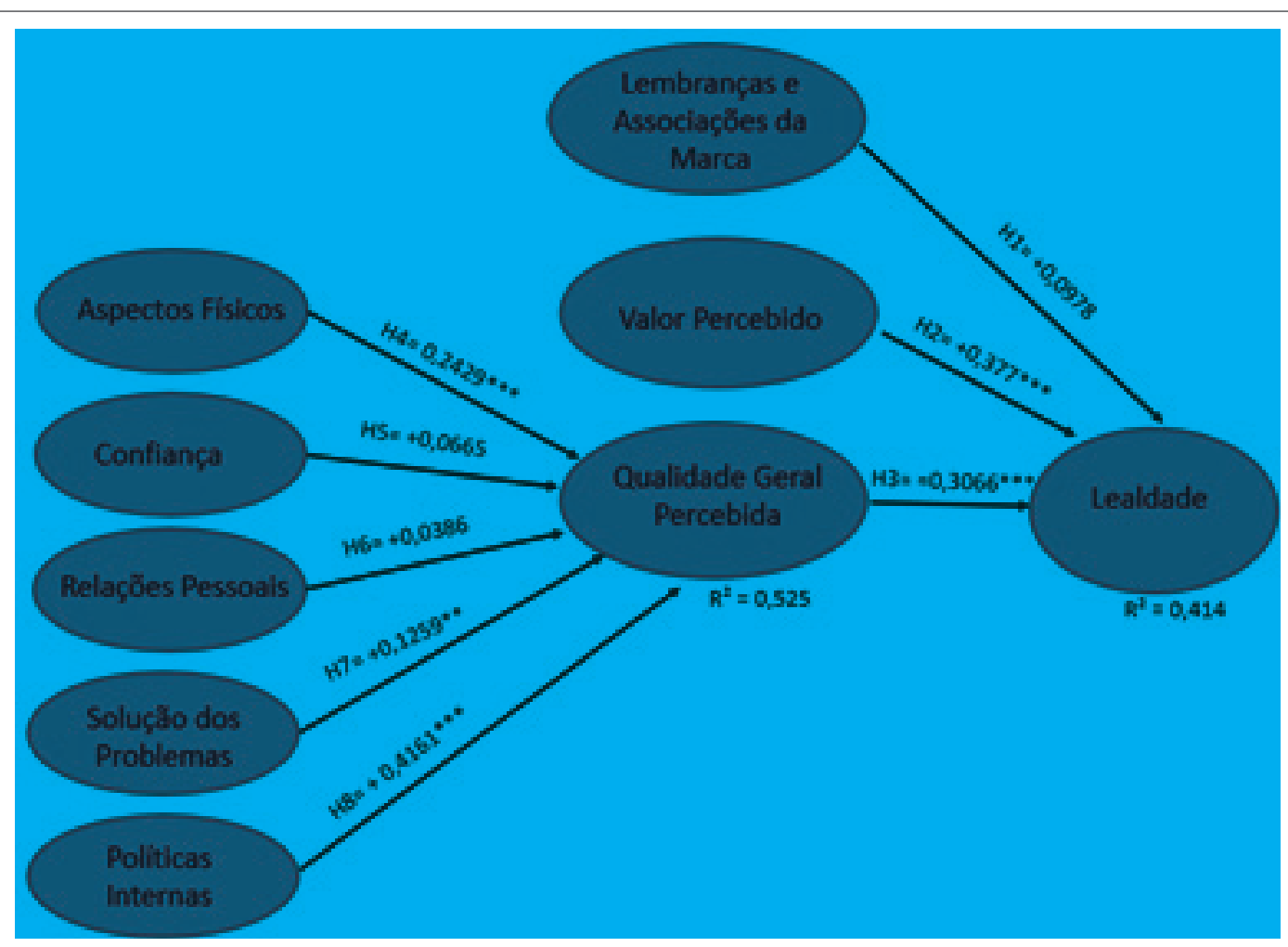

\section{FIGURA 2 - Modelo Estrutural Proposto.}

Fonte: Elaboração própria.

Legenda: $\mathrm{R}^{2}$ - coeficiente de determinação; ${ }^{* * *},{ }^{* *}$ estatisticamente significantes ao nível de $1 \%$ e $5 \%$ respectivamente. 
ciações da marca não influenciam a lealdade dos clientes desse segmento. Contrapondo - resultado encontrado nesta pesquisa, outros estudos (como em FIGUEIRÊDO; RODRIGUEZ; BARROS, 20I5) afirmam que o elo entre o cliente e a marca é um dos principais responsáveis pela decisão de consumo. Porém, este estudo apresentou evidências que, no segmento de restaurantes self-service, as lembranças e associações com a marca não influenciam na lealdade dos clientes. Isto pode ser porque, conforme postula 0 marketing em pequenas e médias empresas (ZOSCHKE; LIMA, 2006), a maioria dos restaurantes self-service são pequenas e médias empresas, que normalmente não possuem marcas e logos fortes, e não costumam investir em propaganda. Essa associação da lembrança da marca com a escolha do restaurante é mais comum ocorrer ao se tratar de franquias conforme dizem Figueirêdo, Rodriguez e Barros (20I5), pois elas possuem, na maioria das vezes, suas marcas e logos mais consolidados. Porém, as franquias representam um percentual pequeno dos self-services.

$A$ influência que o valor percebido da marca exerce na lealdade dos clientes, abordada pela hipótese 2, indicou 0,377 e foi suportada ( $p$-valor $<0,0$ l). Logo, de acordo com a presente pesquisa, o valor percebido influencia a lealdade dos clientes de restaurante self-service. A literatura apresenta que a lealdade é uma das principais consequências do valor percebido pelos clientes (por exemplo, BACELAR; TRINTA; CAMPOMAR, 20I0). Ao falar de restaurantes por quilo entende-se que um cliente atribui valor ao serviço quando ele acredita que $\circ$ valor pago pela refeição, além de justo, lhe trouxe benefícios, fazendo com que ele repita a compra assidua- mente e recomende o restaurante. Assim, o valor percebido do serviço pelo consumidor pode construir a lealdade deste consumidor (ESPINOZA; HIRANO, 2003).

A hipótese 3 , que representou a influência que a qualidade geral percebida exerce na lealdade dos clientes de restaurantes self-service, apresentou coeficiente positivo $(0,307)$ e significativo ( $p$-valor $<0,0$ I), sendo suportada. Diante do exposto, constatou-se que a qualidade percebida influencia a lealdade dos clientes de restaurantes self-service. Corroborando com o resultado encontrado, os resultados de Bergamo, Giuliani, Camargo et al. (20I2), Purgailis e Zaksa (20I2) e Shao-Chang (20I3) também confirmaram a relação direta e positiva entre a lealdade e a qualidade geral percebida do serviço. De modo análogo, os resultados aqui encontrados sugerem que quando o cliente enxerga o restaurante self-service como uma boa opção de alimentação fora de casa, e enxerga qualidade na prestação do serviço que lhe foi oferecido, como consequência, a lealdade do consumidor pode ser construída, assim como aponta a literatura para outros tipos de restaurantes (como em LEAL, 20I0).

O coeficiente de determinação da relação entre a lealdade dos clientes de restaurantes self-service e seus antecedentes diretos testados no modelo proposto neste estudo (lembranças e associações da marca, valor da marca e qualidade percebida do serviço) foi de $4 \mathrm{I}, 4 \%$, sendo que somente valor percebido e qualidade percebida foram significativos. Este percentual representa $\circ$ quanto os dois construtos significativos antecedem a lealdade. Pelo percentual obtido, outros antecedentes, não presentes no modelo proposto, complementam a construção da lealdade dos clientes de restaurante self-service. 
Com propósito de identificar se os fatores da escala QPS influenciam a qualidade geral percebida dos clientes de restaurantes self-service, foram geradas as hipóteses 4 , 5, 6, 7 e 8. Como apresenta a Figura 2, o $R^{2}$ ajustado foi de 0,525 , o que significa que a qualidade percebida pelo cliente pode ser explicada em $52,5 \%$ por três dos cinco construtos que formam a qualidade geral percebida do serviço prestado: aspectos físicos, solução dos problemas e políticas internas.

A hipótese 4 , que abordou a influência dos aspectos físicos na qualidade geral percebida dos serviços nesse segmento, indicou 0,2429 e foi suportada ( $p$-valor $<0,0$ I). Portanto, os aspectos físicos tendem a influenciar a qualidade percebida dos clientes de restaurantes por quilo. Corroborando com os achados de Figueirêdo, Rodriguez e Barros (2015), esta pesquisa encontra que os aspectos físicos dos restaurantes que estão atrelados a imagem que eles passam para os consumidores, por meio da percepção da limpeza dos restaurantes, materiais e ambientes visualmente agradáveis, antecedem a percepção de qualidade geral do estabelecimento. Os restaurantes self-service são projetados de maneira que facilite aos clientes montar suas refeições. Sendo assim, é relevante que se tenha uma acessibilidade fácil, isto é, facilidade de locomoção para acessar o alimento e uma boa gestão e manutenção do buffet, ofertando ao cliente os alimentos que ele deseja para que ele tenha uma percepção de qualidade do serviço (LEAL, 20I0). Estudo anterior sobre aglomeração e a percepção da qualidade no atendimento também constatou a relação direta e positiva entre os aspectos físicos e a qualidade geral percebida do serviço (LOPES; HERNANDEZ; NOHARA, 2009).
A relação entre confiança e qualidade percebida pelos clientes de restaurantes self-service, tratada pela hipótese 5 , foi rejeitada ( $p$-valor $=0,22$ ). Sendo assim, a confiança demonstrou não influenciar a qualidade geral percebida dos clientes desse segmento. A qualidade percebida, pela percepção do consumidor, tem sido relacionada com a confiança em outros estudos, como o de Oliveira, Marcondes, Malere et al. (2009), que defendem que a empresa precisa passar confiança para o cliente, o que facilita a escolha pelo serviço e que ela é imprescindível porque os clientes são multiplicadores em potencial de novos clientes. No entanto, o resultado desta investigação indicou que essa relação pode não existir no segmento de restaurantes self-service, contrariando os achados de Gambarino e Johnson, (1999), que afirmam que a confiança é variável fundamental nos relacionamentos entre consumidores e empresas, pois pode influenciar a qualidade percebida do serviço. Tendo em vista que os restaurantes self-service possuem a particularidade de alcançarem um público flutuante, por causa de praticidade, localização, variedade, entre outros, a confiança talvez não seja um aspecto que venha a interferir na qualidade geral percebida, sendo tal qualidade atribuída a outros elementos, como demonstrado nas demais hipóteses deste estudo.

A influência que as relações pessoais exercem na qualidade geral percebida do serviço pelos clientes de restaurantes selfservice, abordada pela hipótese 6 , foi rejeitada $(p$-valor $=0,61)$. Logo, de acordo com a presente pesquisa, as relações pessoais não influenciam a qualidade percebida dos clientes de restaurante self-service. Estudo anterior aponta que no atendimento, onde 
ocorre boa parte das relações pessoais, é necessário que a empresa crie experiências positivas e mostre que seus funcionários são capazes de atender as demandas de modo satisfatório para que o cliente perceba a qualidade do serviço (OLIVEIRA, MARCONDES, MALERE et al., 2009; LAX, 20 I 2; RYCHALSKI; HUDSON, 201 7; DORNAS; MESQUITA; PATROCÍNIO, 20l4). Porém, a presente pesquisa apresenta evidências que, para os clientes de restaurantes self-service, as relações pessoais não interferem na qualidade percebida do serviço. Pode ser que essa relação não ocorra porque em restaurantes por quilo o próprio cliente monta sua refeição, pois esse segmento trabalha com o autosserviço. Sendo assim, a interação com os colaboradores de restaurantes self-service ocorre de forma pontual, o que contribui para que relações pessoais não estejam relacionadas com a qualidade geral percebida nesse segmento.

A hipótese 7, que representou a influência que a solução dos problemas exerce na qualidade geral percebida pelos clientes de restaurantes self-service, foi positiva $(0,1259)$ e significativa ( $p$-valor $<0,05)$, sendo suportada. Diante do exposto, constatou-se que a solução dos problemas tende a influenciar a qualidade percebida dos clientes de restaurantes self-service. Pesquisas anteriores argumentam que o ambiente competitivo e dinâmico obriga as organizações a melhorar a sua prestação de serviços, atendendo as necessidades e solucionando os problemas dos seus clientes (como em LEAL, 2010; LAGES; PIERCY, 20I2). Diante do resultado encontrado nesse estudo, há indícios da importância dos gestores de restaurantes self-service fornecerem treinamentos para garçons, caixas e demais funcionários que possuem contato direto com os consumidores, para melhorarem suas habilidades pessoais e com isso solucionar problemas dos clientes com maior facilidade (LEAL, 2010). Por consequência, possivelmente gera-se uma percepção positiva de qualidade do serviço.

Por fim, a hipótese 8 tratou a influência que as políticas internas dos restaurantes self-service exercem na qualidade percebida pelos seus clientes. Esta hipótese indicou 0,4 I6I e foi suportada ( $p$-valor $<0,0$ I).Assim sendo, as políticas internas tendem a influenciar a qualidade percebida dos clientes desse segmento. As políticas internas contemplam a qualidade dos alimentos, a presença de estacionamentos, os horários de atendimento, variedade das formas de pagamento e a flexibilidade de pagamento para clientes assíduos. Muitos restaurantes self-service possuem clientes que são frequentadores assíduos, normalmente trabaIhadores ou moradores das redondezas, que possuem algumas flexibilidades nas formas de pagamentos por serem clientes frequentes (LEAL, 20I0). De acordo Ross, Sartori e Godoy (2009), atributos e políticas internas são diretamente proporcionais ao grau de desempenho e qualidade percebida do serviço pelo cliente.

Em resumo, o modelo estrutural permitiu algumas constatações sobre a lealdade de clientes de restaurantes self-service. Os resultados sugerem que a lealdade dos clientes de restaurantes self-service indica ser influenciada pelo valor percebido e qualidade geral percebida. Outra constatação da pesquisa mostrou que a qualidade geral percebida é influenciada pelos construtos aspectos físicos, soluções de problemas e políticas internas. Se a definição de lealdade diz que a relação do cliente e o 
serviço tem característica especial, porque cria um vínculo como resultado, os aspectos desenvolvidos e verificados empiricamente conduzem à orientação na atuação do gestor no intuito de fornecer subsídios aos restaurantes self-service em como obter clientes leais. Orientada pela constatação do potencial do valor percebido e da qualidade geral percebida como elementos influenciadores da lealdade, a presente pesquisa apresenta explicações da formação da lealdade neste tipo de negócio, algo pouco explorado em virtude do restaurante self-service ser, a priori, um tipo de estabelecimento que apresenta dificuldades em obter clientes leais (FIGUEIRÊDO; RODRIGUEZ; BARROS, 20I5).

\section{CONCLUSÃO}

O presente estudo buscou investigar se as lembranças e associações da marca, valor percebido e qualidade geral percebida do serviço influenciam diretamente a lealdade dos clientes de restaurantes self-service. E, se os fatores da escala QPS, aspectos físicos, confiança, relações pessoais, solução de problemas e políticas internas exercem influência direta e positiva na percepção de qualidade dos consumidores desse segmento. Os resultados apontaram que o valor da marca e a qualidade percebida influenciam positivamente a lealdade dos clientes de restaurantes self-service. E três dos cinco construtos presentes na escala QPS, aspectos físicos, soluções dos problemas e políticas internas, influenciam na percepção de qualidade dos consumidores.

Isso permitiu concluir que, quanto maior for a qualidade geral percebida dos serviços dos restaurantes self-service, e quanto mais eles forem vistos como uma boa opção de alimentação fora do lar, acres- centando valor a alimentação dos clientes, provavelmente maior será a lealdade de seus clientes, algo não observado anteriormente na literatura, pois estudos de lealdade em restaurantes são raros, especialmente os self-service. Por sua vez, a qualidade geral percebida pode ser construída por meio da limpeza dos ambientes e utensílios do restaurante, layout adequado que facilite a locomoção do cliente ao se servir, ambiente agradável, funcionários habilitados para solucionarem possíveis problemas que eventualmente possam ocorrer, horários de funcionamento adequados, variedade de formas de pagamento, formas de pagamento diferenciadas para clientes assíduos, e estacionamentos. Esta constatação parece ser semelhante a de outros restaurantes, porém é preciso destacar que o self-service possui particularidades, como o cliente construir seu prato, personalizando-o (algo pouco comum em outros tipos de restaurante), há pouco ou nenhum apoio de garçons, normalmente é mais barato que restaurantes a la carte, entre outros. Consequentemente, a importância atribuída pelos clientes por conveniência e praticidade leva a uma percepção de qualidade própria do tipo de restaurante investigado, como observado aqui.

A presente pesquisa traz como contribuição teórica evidências de antecedentes da lealdade dos clientes de restaurantes self-service, lacuna de pesquisa existente até o presente momento, afinal a literatura anterior aborda outros tipos de restaurante e raramente estuda a lealdade neste tipo de negócio. Assim, a principal novidade deste estudo é a investigação em restaurantes self-service. Como contribuição prática à gestão de restaurantes self-service, esta pesquisa traz informações, dados 
e direcionamentos no investimento para consolidação da lealdade dos clientes com os estabelecimentos em questão, visto que não foram encontrados estudos anteriores sobre a lealdade em restaurantes self-service, bem como o estudo de lealdade de clientes de restaurantes é algo incomum na literatura. Em resumo, o estudo releva elementos que podem ser úteis aos gestores no desenvolvimento da lealdade de seus clientes.

Entende-se como uma limitação da pesquisa a provável existência de outros construtos diferentes dos oito construtos testados, que podem revelar novos antecedentes diretos e indiretos da lealdade dos clientes de restaurantes self-service. Portanto, recomenda-se em pesquisas futuras a inclusão de novos construtos (atitude com relação à alimentação, percepção de preços, satisfação, qualidade percebida de alimentos, status, entre outros) para aprofundar os achados encontrados aqui, pois os resultados indicam que outras variáveis também tendem a influenciar a lealdade dos clientes de restaurantes self-service. Além disso, como a amostragem foi não proba- bilística e por acessibilidade, os resultados encontrados não podem ser generalizados. Por outro lado, estes resultados oferecem evidências que podem ser confirmadas em estudos posteriores.

Sugere-se ainda que, em pesquisas futuras, possam ser analisados clientes por região ou grupos específicos a partir de suas características sócio demográficas, visto o grande número de restaurantes self-service com público e qualidade distintas. Outra especificidade desse segmento que pode ser estudada refere-se às categorias de restaurantes self-service, como os self-service vegetarianos, os de comida caipira, os veganos, os funcionais, dentre outros.Além da inclusão de novos construtos, pode-se utilizar outras escalas que meçam a qualidade do serviço e que identifiquem outros antecedentes da lealdade com a finalidade de comparar com os resultados encontrados nesta pesquisa. A importância atribuída a este trabalho encontra-se em consonância com os interesses em ampliar o conhecimento do tema proposto além de possibilitar o desenvolvimento das questões que envolvem a percepção da lealdade dos clientes de restaurantes self-service. 
ABIA - ASSOCIAÇÃO BRASILEIRA DAS INDÚSTRIAS DA ALIMENTAÇÃO. Vendas da indústria da alimentação para o varejo alimentício e para o food service. 2017. Disponível em: <http://www.abia. org.br/vsn/anexos/mercadointerno20 I6.pdf>. Acesso em: 26 jun. 2017.

AKSOY, L.; KEININGHAM, T.; BUOYE, A.; LARIVIERE, B. Does loyalty span domains? Examining the relationship between consumer loyalty, other loyalties and happiness. Journal of Business Research, v. 68, n. 12, p. 2464-2476, 2015.

AZEVEDO, L. G. M. R. P.; MOURA, L. R. C.; SOUKI, G. Q. Os atributos e suas respectivas dimensões considerados na avaliação do consumidor no processo de escolha de restaurantes. In: $\mathrm{XXXIX}$ ENCONTRO DA ANPAD, 20I5, Belo Horizonte. Anais eletrônicos... 2015.

BACELAR, F.; TRINTA, J.; CAMPOMAR, M. Avaliação de marcas: estudo comparativo de diferentes modelos na ótica de marketing. Revista Alcance, v. I8, n.2, p.46-62, 2010.

BERGAMO, F. V. M.; GIULIANI, A.C; CAMARGO, S.H. C. R. V.; ZAMBALDI, F.; PONCHIO, M. C. A Lealdade do estudante baseada na qualidade do relacionamento: uma análise em instituições de ensino superior. Brazilian Business Review, v. 9, n. 2, p. 47, 2012.

DORNAS, K. B. H.; MESQUITA, J. M. C.; PATROCÍNIO, R. The Relationship between trust, value and loyalty in the Internet Era. Journal of Business and Economics, v. 5, n. 6, p. $802-812,2014$.

ESPINOZA, F.S.; HIRANO, A.S. As Dimensões de avaliação dos atri- butos importantes na compra de condicionadores de ar: um estudo aplicado. Revista de Administração Contemporânea. Rio de Janeiro, v. 7, n. 4, p. 97-I I 7, 2003.

EXAME. Alimentação fora de casa. 20I7. Disponível em:<https://exame.abril.com.br/negocios/dino/ segundo-pesquisa-34-dos-brasileiros-gastam-com-alimentacao-fora-do-lar-shtml/> Acesso em: 15 out. 2017.

FIGUEIRÊDO,M.G.M.; RODRIGUEZ, V. B. C.; BARROS, M. J. F. O consumidor come com os olhos: o poder da identidade visual dos restaurantes de shopping. In: $X X X I X$ ENCONTRO DA ANPAD, 20I5, Belo Horizonte. Anais... 2015.

FORNELL, C.; LARCKER, D. F. Evaluating structural equation models with unobservable variables and measurement error. Journal of Marketing Research, v. 18, n. I, p. 39-50, I98I.

FRAERING, M.; MINOR, M. S. Beyond loyalty: customer satisfaction, loyalty, and fortitude. Journal of Services Marketing, v. 27, n. 4, p.334-344, 2013.

GAMBARINO, E.; JOHNSON, M. S. The Diferent Roles of Satisfaction, Trust, and Commitment in Customer Relationships. Journal of Marketing, v. 63, n.2, p. 70-87, 1999.

HAIR JR., J. F., BLACK, W. C.; BABIN, B. J.; ANDERSON, R.E.; TATHAM, R. L. Análise multivariada de dados. 6 ed. Porto Alegre: Bookman. 2009

HONICKY, M.; SCHWARZ, K.; VIEIRA, R. L. D.; FREIRE, P. L. I.; GATTI, R. R. Nível de satisfação e escoIhas alimentares dos comensais em restaurante self-service. DEMETRA: Alimentação, Nutrição \& Saúde, v.I2, n. I, p. 333-346, 2017.
HYUN, S. S. Predictors of relationship quality and loyalty in the chain restaurant industry. Cornell Hospitality Quarterly, v. 5I, n. 2, p. 25I267, 2010.

KANTSPERGER, R.; KUNZ, W. H. Consumer trust in service companies: a multiple mediating analysis. Journal of Service Theory and Pratice, v. 20, n. I, p. 4-25, 2010.

KANDAMPULLY, J.; ZHANG, T.; BILGIHAN, A. Customer loyalty: a review and future directions with a special focus on the hospitality industry. International Journal of Contemporary Hospitality Management, v. 27, n.3, p. 379-4I4, 2015.

KATHURIA, L.; GILL, P. Purchase of branded commodity food products: empirical evidence from India. British Food Journal, v. I I5, n. 9, p. I255-I280, 2013.

KIM, M. G.; LEE, C. H.; MATTILA, A. S. Determinants of customer complaint behavior in a restaurant context: The role of culture, price level, and customer loyalty. Journal of Hospitality Marketing \& Management, v. 23, n.8, p. 885-906, 2014.

LAGES, C. R.; PIERCY, N. F. Key drivers of frontline employee generation of ideas for customer service improvement. Journal of Service Research, v. I5, n. 2, p. 2I5-230, 2012.

LARÁN, J. A.; ESPINOSA, F. Consumidores satisfeitos e então? Analisando a satisfação como antecedente da lealdade. Revista de Administração Contemporânea, v.8, n.2, p.5I-70, 2004.

LAX, H. L. The experience-loyaltyvalue connection. News Marketing, v. I0, p. 24-27, 2012.

LEAL, D. Crescimento da alimentação fora do domicílio. Segurança Alimentar e Nutricional, v. I7, n.I p. I23-132, 2010. 
LEE, K.; KHAN, M.;HA, I.S.; KO,J.Y.EXploring the impacts of McService on customers' loyalty: An emerging market's perspective. Journal of Foodservice Business Research, v. 20, n. 7, p. I-13, 2017.

LOPES, E. L.; HERNANDEZ, J. M. C.; NOHARA, J.J. Escalas concorrentes para a mensuração da qualidade percebida: uma comparação entre a Servqual e a RSQ. RAE: Revista Administração de Empresas, São Paulo, v. 49, n. 4, p. 40I416, 2009.

MURAD, F. B.; TORRES, D. F. Marcas próprias e valor de uma marca: o estudo de caso da marca própria Carrefour. In: Encontro Anual da Associação Brasileira dos Programas de Pós-Graduação em Administração, Anais..., Rio de Janeiro, 2008.

NGUYEN, N.; LEBLANC, G. Image and reputation of higher education instituions in student's retention decisions. The International Journal of Education Management Bradford, v.15, n. 6, p. 303-3II, 2001.

OLIVEIRA, E. G.; MARCONDES, K. S.; MALERE, E. P.; GALVÃO H. M. Marketing de serviços: relacionamento com o cliente e estratégias para a fidelização. Revista de Administração da Fatea, v. 2, n. 2, p. 79-93, 2009.

OLIVER, R. L. Whence consumer loyalty? Journal of Marketing, v. 63, n. 4(suppl I), p. 33-44, 1999. PERMARUPAN, P.; MOHAN, M.; AL -MAMUN, A.; ZAINOL, N. Consumer perceived value and buying behavior of store brands. International Business Management, v. 8 , n. 2, p. $|36-| 4|, 20| 4$.

PIGATTO, G. Cadeia de suprimentos de perecíveis: como restaurantes selecionam e se relacionam com fornecedores de hortaliças. Economia \& Região, v.5, n.l, p. 7-30, 2017.

PURGAILIS, M.; ZAKSA, K. The impact of perceived service quality on student loyalty in higher education institutions. Journal of Business Management, v.6, n. 6, p. I38-|52, $20 \mid 2$.

REBELATO, M. G. Uma análise sobre a estratégia competitiva e operacional dos restaurantes self-service. Revista Gestão \& Produção, v. 4, n. 3, p. 32I-334, 1997.

RYCHALSKI, A.; HUDSON, S. Asymmetric effects of customer emotions on satisfaction and loyalty in a utilitarian service context. Journal of Business Reseacrch, v.7I, p. 84-9I, 2017.

ROSS, C.; SARTORI, S.; GODOY, L. Modelo de Kano para a identificação de atributos capazes de superar as expectativas do cliente. Revista Produção Online, v. 9, n. 3, p. 536-550, 2009.

ROSSEAU, D; SITKIN, S. B.; BURT, R. S.; CAMERER, C. Not so different
After All: a cross discipline view os trust. Academy of Management Review, v. 23, n. 3, p. $393-404$, 1998.

SHAO-CHANG, L. Explore the relationships among service quality, customer loyalty and word-of mouth for private higher education in Taiwan. Asia Pacific Management Review, v. I8, n. 4, p. 24582469, 2013.

WIEN, A. H.; OLSEN, A.O. Evaluation context's role in driving positive word-of-mouth intentios. Journal of Consumer Behaviour, v. II, n. 6 , p. 504-5I3, 2012.

WIESEKE, J.; ALAVI, S.; HABEL, J. Willing to Pay More, Eager to pay less: the role of customer loyalty in price negotiations. Journal of Marketing, v. 78, n. 6, p. 17-37, 2014.

YOO, B.; DONTHU, N. Developing and validating a multidimensional consumer-based brand equity scale. Journal of Business Research, v. 52, n. I, p. I-I4, 200 I.

ZEITHAML, V. A. Consumer perceptions of price, quality, and value: a means-end model and synthesis of evidence. Journal of Marketing, v. 52, n. 3, p. 2-22, 1988.

ZOSCHKE, A. C.; LIMA, E. O. Marketing empreendedor e redes de relação: Um estudo sobre micro, pequenas e médias empresas. Gestão e Planejamento, vol. 7, n. 14, 2006. 


\section{APÊNDICE}

\begin{tabular}{|c|c|c|}
\hline \multicolumn{3}{|c|}{ Estrutura dos construtos e Indicadores } \\
\hline Construtos/ Referências & \multicolumn{2}{|r|}{ Variáveis } \\
\hline \multirow{3}{*}{$\begin{array}{l}\text { Leald ade a marca } \\
\text { (MURAD; TORRES, 2008) }\end{array}$} & $\mathbf{L}$ & comparad o a outros tipos de restaurante, eu me considero leal a restaurantes self-service. \\
\hline & 12 & Restaurante self-service é minha primeira opção. \\
\hline & $\mathbf{L}$ & Au não vou a outros restaurantes se existe al gum restaurante self-service disponivel. \\
\hline \multirow{6}{*}{$\begin{array}{l}\text { Qualidade Percebida } \\
\text { (MURAD; TORRES, 2008) }\end{array}$} & QP1 & Comparad o a outros tipos de restaurante, restaurantes self-service são de alta qualidade. \\
\hline & QP2 & Bu espero que a qualidade de restaurantes self-services seja sempre extremamente alta. \\
\hline & QP3 & Se é restaurante self-service, deve ser de muito boaqualidade. \\
\hline & QP4 & Jamais restaurantes self-service são de baixa qualidade. \\
\hline & QP5 & A chance que um restaur ante self-service ser uma boa opção é muito alta. \\
\hline & QP6 & A probabilidade de que restaurantes self-service sejam confiáveis é muito alta. \\
\hline \multirow{6}{*}{$\begin{array}{c}\text { Lembranças e } \\
\text { associações da marca } \\
\text { (MURAD; TORRES, 2008) }\end{array}$} & LM1 & Au sei reconhecer um restaurante self-service de d to nivel \\
\hline & LM2 & au posso identicar um restaurante self-service de alto nivel entre outros restaurantes. \\
\hline & LM3 & Eu conheço bem restaurantes self-service. \\
\hline & LM4 & Algumas caracteristicas de restaur antes self-service vem a minha mente rapidamente. \\
\hline & LMS & Eu rapidamente posso lembrar o símbolo ou logotipo de algum restaurante self-service. \\
\hline & LM6 & Eu não tenho dificuld ade de imagina um bom restaurante self-service na minha cabeç. \\
\hline \multirow{4}{*}{$\begin{array}{l}\text { Valor da marca geral } \\
\text { (MURAD; TORRES, 2008) }\end{array}$} & VP1 & $\begin{array}{l}\text { Vale a pena se alimentar em um restaurante self-service ao invés de em outros restaurantes } \\
\text { mesmo quando eles são semelhantes. }\end{array}$ \\
\hline & VP2 & $\begin{array}{l}\text { Mesmo que outros restaurantes tenham a mesmas características, eu prefiro ir em um } \\
\text { restaurante self-service. }\end{array}$ \\
\hline & VP3 & $\begin{array}{l}\text { restaurante self-service. } \\
\text { Mesmo que haja outro restaurante tão bom quanto, eu prefiro restaurantes self-service. }\end{array}$ \\
\hline & VP4 & $\begin{array}{l}\text { Se outro restaurante não é em nada diferente, parece mais inteligente ir a um restaurante self- } \\
\text { service. }\end{array}$ \\
\hline \multirow{6}{*}{$\begin{array}{l}\text { Aspectos físicos } \\
\text { (LOPES; HERNANDEZ; } \\
\text { NOHARA, 2010) }\end{array}$} & AF1 & Restaurantes self-service normalmente tem equipamentos modernos. \\
\hline & AF2 & Os ambientes dos restaurantes self-services são visualmente agradáveis. \\
\hline & AF3 & Os materiais usad os em restaurantes self-service são visualmente agradáveis. \\
\hline & AF4 & A limpeza dos restaurantes self-service, induindo banheiro, é ad equada. \\
\hline & AF5 & Oloyout dos restaurantes self-service facilita o diente encontrar oque precisa. \\
\hline & Af6 & Oloyout dos restaurantes self-service facilita a locomoção do diente. \\
\hline \multirow{5}{*}{$\begin{array}{c}\text { Confiança } \\
\text { (LOPES; HERNANDEZ; } \\
\text { NOHARA, 2010) }\end{array}$} & CON1 & Quando restaurantes self-service prometem algo, cumprem dentro do que foi informado. \\
\hline & $\operatorname{CON} 2$ & Os restaurantes self-service cumprem suas promessas. \\
\hline & CON3 & Os restaurantes self-service sempre realizam serviços de maneira correta. \\
\hline & CON 4 & Os restaurantes self-service mantém disponíveis os alimentos que os dientes desejam. \\
\hline & CON5 & Os restaurantes self-service se esforçam para manter o registros de seus dientes frequentes. \\
\hline \multirow{10}{*}{$\begin{array}{l}\text { Relações pessoais } \\
\text { (LOPES; HERNANDEZ; } \\
\text { NOHARA, 2010) }\end{array}$} & RP1 & Os empregados dos restaurantes self-service têm con dições de sana as dúvida dos dientes. \\
\hline & RP 2 & O comportamento dos funcionários dos restaurantes self-service inspira confiança aos dientes. \\
\hline & RP3 3 & Os dientes se sentem seguros em realizar refeições em restaurantes self-service \\
\hline & RP 4 & $\begin{array}{l}\text { Os empregad os dos restaurantes self-service estão sempre disponiveis para aten der a diente. } \\
\text { Os empregad os dos restaurantes self-service prestam informaçoes corretas sobre os serviços }\end{array}$ \\
\hline & RP5 & realizados. \\
\hline & & Os empregad os dos restaurantes self-service estão sempre disponíveis para sanar as dúvidas dos \\
\hline & RP 6 & dientes. \\
\hline & RP 7 & Os restaurantes self-service dão atendimento personalizados a seus dientes. \\
\hline & RP 8 & Os empregad os de restaurantes self-service sempre são cordiais. \\
\hline & RPg & $\begin{array}{l}\text { Os empregad os de restaurantes self-service atendem bem também ao telefone (encomendas, } \\
\text { dúvidas, etc). }\end{array}$ \\
\hline \multirow{4}{*}{$\begin{array}{l}\text { Solução de Problemas } \\
\text { (LOPES; HERNANDEZ; } \\
\text { NOHARA, 2010) }\end{array}$} & SP1 & $\begin{array}{l}\text { Quando ocorre algum problema (por exemplo, derrubar o prato, excesso de sal, etc), os } \\
\text { restaurantes self-service facilitam as trocas das refeiçōes. }\end{array}$ \\
\hline & SP2 & $\begin{array}{l}\text { Quando o diente tem um problema, os restaurantes self service mostram interesse sincero em } \\
\text { resolver. }\end{array}$ \\
\hline & & Os empregados dos restaurantes self-service são habilitados a solucionar pessodimente os \\
\hline & SP3 & problema dos dientes. \\
\hline \multirow{6}{*}{$\begin{array}{l}\text { Políticas Internas } \\
\text { (LOPES; HERNANDEZ; } \\
\text { NOHARA, 2010) }\end{array}$} & PI1 & Restaurantes self-service sem pre oferecem produtos de atto padrão. \\
\hline & $\mathbf{P} 12$ & $\begin{array}{l}\text { Os restaurantes self-service costumam disponibiliza altemativas de estacionamento aos } \\
\text { dientes. }\end{array}$ \\
\hline & & Os horários de funcion amentos dos restaurantes self-service são convenientes para os seus \\
\hline & PI3 & \\
\hline & $\mathbf{P} 14$ & Os restaurantes self-service aceitam variadas formas de pagamento. \\
\hline & P15 & $\begin{array}{l}\text { Restaurantes self-services of erecem formas de pagamento es peciais para os seus dientes } \\
\text { asiduos. }\end{array}$ \\
\hline
\end{tabular}

